Myers, J. E. (1983). Rehabilitation counseling for older disabled persons: The state of the art. Journal of Applied Rehabilitation Counseling, 4(3), 47-53.

Made available courtesy of The National Rehabilitation Counseling Association: http:/nrca-net.org/

\title{
Rehabilitation Counseling for Older Disabled Persons: The State of the Art
}

By Jane E. Myers

\section{Abstract}

Disabled older persons are a population traditionally excluded from rehabilitation services because they were considered unfeasible for substantial gainful employment. The emerging focus on independent living services, along with increases in the average life span and changes in policies such as mandatory retirement age, has forced a reexamination of the potential for rehabilitation of this population. This article examines what is known about disabled older people, including both medical and psychosocial aspects, and discusses the implications of these conditions for rehabilitation planning. The definition of the state of the art in working with older persons includes attention to counseling practices and concludes with resources for additional information.

One-third of all functionally disabled persons are aged 65 or over (Rehab. Group, 1979), an age that represents $12 \%$ of our total population or "every ninth American" (Brotman, 1982). Those who reach their seventh decade are definitely survivors, and their potential for living actually increases! More specifically, while the average life expectancy of someone born today is 73.3 years, a person who is 65 today can expect to live an average of 16.3 more years, for a total of 81.3 (Brotman, 1982).

Since the inception of a formal state-federal rehabilitation program, the focus of services has been on persons "of working age." Rehabilitation counselors have been legislatively mandated to focus their efforts on younger persons. The passage of the Comprehensive Services, Developmental Disabilities and Rehabilitation Services Amendments of 1978, especially the Title VII provisions for independent living rehabilitation (ILR), has raised the question of what to do about older people (Williams, 1981). Rehabilitation counselors are faced with an enormous and multifaceted challenge in regard to this population, for several reasons. First, their training, both in and pre-service, has excluded attention to the needs of older people. Second, the underlying philosophy of vocational rehabilitation (not to mention the 26-closure "reward" system) has naturally excluded older people from service consideration. Third, social prejudice against older people, combined with the first three facts, has created a situation wherein rehabilitation counselors often view older people as having little or no rehabilitation potential (Benedict \& Ganikos, 1981; Rasch, Crystal, \& Thomas, 1977).

In order to meet this challenge effectively, rehabilitation counselors need a variety of information about older disabled people. This article provides a review of the state of the art in regard to rehabilitation counseling with this population. It begins with a definition of older disabled people, including medical conditions and functional limitations, follow- ed by a discussion of psychosocial considerations. The implications for rehabilitation planning are discussed, followed by a review of counseling practice with regard to clientele. The article concludes with a list of available resources to assist counselors in learning about and working with older disabled people.

\section{Toward a Definition of Aging and Disability}

"Rehrabilitation of the aged is a meaningless phrase. At best, it merely insinuates that all aged persons need to be rehabilitated" (Wolcott \& Wheeler, 1971, p. 279). This quote exemplifies a major problem in rehabilitating older people - that of defining the eligible client population. Old age is not a disease. In fact, there are no specific diseases or illnesses characteristic of older people exclusively (Radzyminski, 1969; Rusk, 1977). Even Sehile Dementia of the Alzheimers Type (SDAT) is known to occur as early as age 40 (National Institute on Aging, 1981). It thus becomes necessary to examine the following factors: a definition of old age, a definition of aging, per se, common health problems of older people, disability among older people, and the impact of disabling conditions on functional limitations.

What is "old" depends on who is asked. For example, the Age Discrimination in Employment Act (PL 90-202) covers "older workers" between the ages of $\mathbf{4 0}$ and 70 . Social Security benefits are available for "old" people at age 65, and disabled old people at age 62 . The World Health Organization defines middle age as 45-59, elderly at 60-74, and aged 75 and over (in Puner, 1974), and the old-old, ages 75 and above (Youmans, 1977). Changes in mandatory retirement age legislation further complicate the issue.

An alternative approach is to consider a functional definition of old age, based on known facts about the aging pro cess. Unfortunately, this process is not well understood. Wolcott and Wheeler (1971) distinguish between primary aging, which is due to the passage of time, and secondary aging, which results from declines in functional efficiency due to severe trauma or chronic debilitation. Jernigan (1981) notes that aging begins at conception and the first signs of decline occur soon after puberty. Gradual and irreversible change occurs throughout the lifespan, affecting all body systems adversely (Macione, 1979). True aging may thus be defined as incorporating four major characteristics: it is universal, progressive, decremental, and intrinsic (Strehler, 1962). 
Myers, J. E. (1983). Rehabilitation counseling for older disabled persons: The state of the art.

Journal of Applied Rehabilitation Counseling, 4(3), 47-53.

Made available courtesy of The National Rehabilitation Counseling Association: http://nrca-net.org/

\section{Volume 14, Number 3, Fall 1983}

Biological aging, which occurs at varying rates in different people, is affected by genetic inheritance, lifestyle, disease and psychological coping behaviors (Jernigan, 1981). Normal biological changes affect all aspects of life, and result in decreased physical ability to adapt to change (Goldman, 1971), as well as predisposing the aged person to both acute and chronic illness (Macione, 1979). Normal aging changes may be insidious and develop so gradually that the aging individual either is unaware of them or progressively adapts with little need for outside intervention (Butler, 1975).

In regard to health problems, basically rehabilitation counselors will encounter two types of older clients (Jernigan, 1981). The first group is comprised of individuals who led normal, healthy lives until the progressive decrements of aging resulted in physical limitations. The second group are those persons who became disabled sometime between conception and old age, and whose existing diseases and disabilities are further complicated by the normal processes of aging.

The primary conditions contributing to disability in old age are the same ones leading to death, since it may be presumed that physiological change and decline contribute to mortality (Blake, 1981). The 10 leading causes of death in old people, in descending order or prevalence, are: diseases of the heart; malignant neoplasms; cerebrovascular disease; influenza and pneumonia; arteriosclerosis; diabetes mellitus; accidents; bronchitis, emphysema and pneumonia; cirrhosis of the liver; and nephritis and nephrosis (Siegal, 1978). Three fourths of all deaths among older people are attributed to the first three conditions (Brotman, 1982). Noninstitutionalized older persons, who comprise some $95 \%$ of the total elderly population, most frequently report having the following chronic conditions (Brotman, 1982): arthritis (44.3\%), hypertension $(38.5 \%)$, hearing impairments $(28.2 \%)$, heart disease $(27.4 \%)$, arteriosclerosis $(12.0 \%)$, visual impairment $(11.95 \%)$, and diabetes $(8 \%)$.

It is obvious from the preceding discussion that many older people have multiple impairments. These both lead to and interact with additional diseases. Multiple pathology is the rule, and multiple conditions must be treated simultaneously (Cape, 1978). Accurate assessment of medical problems is essential, though complex (Jernigan, 1981; Schow, Christensen, Hutchinson \& Nervonne, 1978). It is important to recognize that both prevention and correction are possible and desirable, and depend to an extent on recognition that "although not preventable or reversible, aging is not disabling under normal conditions" (Gryfe, 1978, p. 238).

Generally, as compared to persons of younger age, old people tend to get sick more often, have more chronic illness, often have multiple health problems, and have both more and longer hospital stays (Blake, 1981; Harel, Scollod \& Bognar, 1982). Persons over age 65 have twice as much disability and four times as much activity limitation as those under 65 (Brotman, 1982). An estimated $86 \%$ of all older persons suffer from one or more chronic health problems that in some way restrict their activities of daily living (Brotman, 1976). Davis and Onyemelukwe (1977, p. 460) estimate that $35 \%$ of older persons "have some disability serious enough to limit their capacity to work, keep house, or engage in other major activities."
In addtion to physical conditions, a large proportion of older persons suffer from some form of mental impairment. If detected and treated, these conditions often are reversible (Cohen, 1977).

Thus, virtually the entire gamut of possible disabling conditions may be seen in older clients. Functional limitations may vary based on severity of the disease or diseases involved, and the existence of multiple and interacting conditions. Most conditions of older people are chronic and progressive. Individual assessment is essential to identify residual capacities and functional limitations, which vary considerably across individuals and are complicated by the psychosocial factors discussed below.

\section{Psychosocial Aspects}

The population of older persons is both large and heterogeneous. Reactions to disability among older persons are basically the same as are encountered with persons of any age group, and it is difficult to describe psychosocial aspects that are unique to this population. However, it is important to recognize that, while the kinds of needs they have are the same needs experienced by all people, the degree or extent of need among older people varies (Ohio, 1960). In this section, some key psychosocial aspects to consider in working with older clients are discussed, with a focus on those sociological and psychological issues that are most intrinsic to this population.

The oldest and most widely researched topic in social gerontology is that of life satisfaction, or subjective well being, and its relationship to mental health (Liang \& Bollen, 1983). This feeling of contentment or morale is directly related to "successful aging." The major correlates of life satisfaction are socioeconomic status, education, income, age, marital status, formal participation in voluntary and church related activities, visits with friends and neighbors, and perceived health (Chatfield, 1977; Edwards \& Klemmack, 1973).

Factors affecting quality of life over the lifespan are similar for everyone, but some take on increased importance for old people. The five major components are as follows: first is the presence of a spouse; second and third for women are children and work, while for men the two are reversed; fourth is material well-being and fifth, health (Flanagan, 1982). The basic environment that provides old people with happiness and a sense of security is the family unit (Townsend, 1957). Moreover, research has shown the presence of a single confidant to be the one essential factor that mitigates against the negative concomitants of aging and thus helps to maintain feelings of life satisfaction among older people (Lowenthal \& Haven, 1968).

Many of the components of life satisfaction discussed above are not readily available to old people who also are disabled in some way. While a supportive social environment is essential for successful aging (Havighurst, 1968), many older people lack needed support because of the impact of factors such as ageism and loss, especially loss of social roles.

Ageism may be defined as bias against older persons (Butler, 1975) and is similar to sexism, racism and handicapism. Negative attitudes are widespread, and include perceptions of older persons by younger individuals as well 
Myers, J. E. (1983). Rehabilitation counseling for older disabled persons: The state of the art. Journal of Applied Rehabilitation Counseling, 4(3), 47-53.

Made available courtesy of The National Rehabilitation Counseling Association: http://nrca-net.org/

\section{Journal of Applied Rehabilitation Counseling}

as their own age peers (Cameron \& Cromer, 1974; McTavish, 1971). Service providers, including rehabilitation counselors, also tend to have negative attitudes toward old people (Benedict \& Ganikos, 1981).

Social role ambiguity contributes to ageist attitudes (Brine, 1979). Few norms or role expectations exist for older people (Bengston, 1977), whom Burgess (1960) described as being imprisoned in a "roleless role." Aged individuals are expected to accept, gracefully, the loss of social roles, whether or not replacements, such as leisure activities, are readily available. (Refer to the Desiderata, which states "gracefully surrender the things of youth.')

Older persons experience. multiple losses, often simultaneously (Butler \& Lewis, 1983), resulting in substantial coping needs resulting from "bereavement overload" (Kastenbaum, 1969). Social role loss is both inherent in and compounded by many of the losses that accompany old age (Bengston, 1977). Loss of the work role due to retirement may have deleterious effects on feelings of self-worth (Simpson \& McKinney, 1966) as well as on perceived status in the community. Losses tend to lead to increased dependence (Brine, 1979), accompanied by drastic shifts in family relationships (Herr \& Weakland, 1979).

The ways in which older persons cope with loss and disability are as varied as the individuals within this population (Neugarten, 1976). Personality, developed over the lifespan, is a major determinant of characteristic coping styles. Personality in old age is determined primarily by personality before old age (Bengston, 1977). The major change appears to be an increase in introspection, accompanied by a shift in time perspective from time since birth to time left to live (Butler \& Lewis, 1983; Neugarten, 1976).

A major study of personality and aging identified eight major personality types that are well established by middle age and continue into the later years (Neugarten, Havighurst, \& Tobin, 1968). These have been related to successful aging, as well as to major theories of life span development and aging. A discussion of these theories is beyond the scope of this paper; however, the interested reader may find numerous discussions in the literature, as well as a review of each theory in relationship to rehabilitation (in Myers, 1983).

Reactions to loss, including physical losses, are not significantly different for older as compared to younger persons. These include denial and depression (Loyola, 1979; Pfeiffer \& Busse, 1973) as well as anxiety and fear of death (Lawrence, 1981). Salmon (1981b) reviewed the interactive problems of health and disability for old people, and noted that limited personal resources combined with limited societal resources create massive problems for this population. He quotes Chown (1977, in Salmon, 1981b, p. 48) as saying that "the old and ill or disabled may have almost too much to handle." Consequently, rehabilitation counselors, operating with a philosophy of maximizing independence, have much to offer older disabled persons. Some specific suggestions for how they might do this are discussed below.

\section{Rehabilitation Planning}

Considering the functional impact of disability among older persons, and the fact that multiple problems are likely to be encountered, the application of the rehabilitation process can lead to effective interventions. This process in relation to older disabled persons is not remarkably different from its use with young disabled persons (Myers, 1980). Major differences appear in types of referral sources, available resources, and possible outcomes (Bozarth, 1981).

The process begins with a comprehensive and accurate assessment of the client's needs and resources, including attention to medical and psychosocial factors. Prognosis is complicated by a variety of interacting factors, but is important in determining treatment goals and potential for independent functioning. Either independent living or job placement may be the desired and most feasible outcome, or rehabilitation goal.

Comprehensive assessment of older disabled persons must be holistic in nature (Kobrynski, 1966), and must include consideration of historical factors. The pattern of disability often is established prior to old age and is helpful in predicting future patterns (Thomas, 1968). The ORS methodology for multidimensional functional assessment is a tool in common use that incorporates both medical and psychosocial evaluations (Pfeiffer, 1976).

Prognosis is dependent on extent of disability and handicap, available resources, and a variety of both tangible and intangible factors (Myers, 1983). Factors such as available transportation, income, and family or social supports will affect rehabilitation success (Butler \& Lewis, 1982). It is important to consider both mental and physical faculties of the elderly client Good communication, including vision, hearing and speech, are important for interactions with service providers and counselors (Rosenbloom, 1974).

A major barrier affecting the prognosis for success is the prevalent negative attitudes among caregivers (Preston, 1979). These negative attitudes affect policy making, service provision, and the self-concept of older clients (Gaitz, 1974), and substantially inhibit the therapeutic process (Solomon \& Vickers, 1979). Because the diseases of older persons so often are chronic and incurable, maintenance over the lifespan may be required (Butler, 1975). The prognosis for improvement of older disabled clients is good when attitudinal barriers are overcome (Hodgson \& Quinn, 1980).

Rehabilitative treatment is based on the underlying goal of assisting disabled older persons to live independently as long as possible (Hunt, 1980). It is important to recognize that the needs and goals of older persons differ from those of younger people. Disease in younger individuals often affects an otherwise healthy body, whereas disease in older persons may be superimposed on already existing degenerative conditions. For older disabled people, both restoration and rehabilitation always will require medical treatment (Sherman \& Gingras, 1965). There are two primary objectives of this treatment: "(1) for the disabled aged, to increase the functional level and to decrease dependency on others, and (2) for the frail elderly, to prevent disablement which may lead to invalidism"' (Kobrynski, 1966, p. 406). Treatment is aimed at either restoring the ability for self care and ambulation, or at maintaining functioning and preventing decline.

Functional capacities of older disabled persons will determine whether rehabilitation goals are primarily in terms of full or part-time employment or independent living. It may 
Myers, J. E. (1983). Rehabilitation counseling for older disabled persons: The state of the art.

Journal of Applied Rehabilitation Counseling, 4(3), 47-53.

Made available courtesy of The National Rehabilitation Counseling Association: http://nrca-net.org/

\section{Volume 14, Number 3, Fall 1983}

be expected that many young old persons, those aged $60-74$, will be potentially employable, while many old-old individuals, those aged $75+$, will require independent living services.

Many older disabled persons both want to and are capable of working, but are unable to do so because of age discrimination in employment, mandatory retirement, and employer prejudice (Butler \& Lewis, 1982), as well as low levels of education, skill obsolescence and need for retraining (Sheppard, 1971). Dunn (1981) noted that many older workers are both disabled and working for several years. They could maintain employment if appropriate vocational rehabilitation services were provided (Jarvikowski \& Lahelma, 1980). Barriers to employment of older persons have been described elsewhere (see Batten, 1980; Kasschau, 1976; Myers, 1980; Myers, 1983).

A variety of resources exist to provide assistance in job placement of older disabled workers (Myers, 1983). These include the U.S. Employment Service, federal ACTION programs such as Foster Grandparents, the Retired Senior Volunteer Program and the Senior Companion Program, the Senior Community Service Employment Program, and a variety of special older worker projects (see Dunn, 1981; Housman \& Baumann, 1981).

Where vocational goals are impractical, the services required to achieve independent living among older persons are the same as those needed by other disabled people. Older persons, however, may need services for a longer period of time (Williams, 1981). The primary goal is to maintain the older disabled individual in a community setting, preferably in their own home (Goldstone, 1978). A variety of social, medical and support services may be required to achieve independent living, including adapted housing, income maintenance, health care, transportation, shopping assistance and so forth (Smith, 1978; see also Myers, 1983).

ILR settings for older people vary from totally independent housing to congregate living environments to nursing homes, depending on the extent of need for services. Within each setting, the goal is to achieve the maximum possible amount of independent functioning (Campbell, 1979). Such an emphasis on functioning can lead to gainful employment (Lobuts, 1977). In many cases, a critical ingredient in rehabilitation success is the intervention provided by a professional counselor.

\section{Counseling Practice}

Counseling practice with older people is a relatively new area of professional involvement, both for counselors in general and for rehabilitation counselors in particular. In this section, specific uses and techniques of counseling with older disabled clients are reviewed.

Odell stated that "counseling and individualized job development and placement methods can double or even triple the chances of middle aged and older workers for new jobs"' (in Dunn, 1981, p.79). Counselors help both to motivate and remotivate older disabled clients and to build their selfesteem (Organization for Economic Cooperation and Development, 1967). Dunn (1981) suggests that counselors may help older clients understand ways in which their experiences and training can contribute to new employment ob- jectives, as well as how physical declines may be compensated by other abilities.

Counselors can intervene with employers to overcome a variety of barriers to hiring older workers, including the process of dispelling myths about older workers' abilities. Counselors can help older clients to maintain their existing jobs or obtain new jobs, and can assist employers in modifying or restructuring job sites to make either outcome possible (Dunn, 1981; Myers, 1980). Retraining for modified jobs will sometimes be needed (Barkin, 1970, in Dunn, 1981). The least desirable alternative is a change in jobs, because of the loss of status and earnings that result (Dunn, 1981). The counselor's job in this instance is much more difficult. Some attention to retirement preparation or retention preparation can ease the transition from a full-time to part-time or nonwork role.

Counseling is an important service also in achieving independent living goals with older people. It is often most effective on a group basis (Williams, 1981), as it aids the process of peer identification, the sharing of common problems, and the recognition that one is not alone. By helping older person's meet their needs for social services such as housing and transportation, counselors help to satisfy their emotional needs as well (Myers \& Loesch, 1981; Stickle, 1977).

In addition to service coordination, referral and assistance with tangible problem areas, several techniques have proved effective in helping older persons achieve a subjective state of well being, or life satisfaction. The primary counseling technique used with older disabled persons is life review therapy, developed by Butler (1974). Older clients are encouraged to talk about their lives, and the counselor can use the information provided to enumerate the clients' strengths and coping abilities. The conclusion that each individual older person is a "survivor" cannot be ignored.

Building self-esteem is a major concern in counseling with older clients, and may be achieved in a variety of ways. Waters and Weaver (1981) describe ways to help older people using life review therapy, strength bombardment activities, providing assistance in problem solving and teaching assertiveness techniques. Salmon (1981a) adds techniques for building and using support networks to enhance the capabilities of older clients to meet their needs on a continuing basis.

For those older clients whose impairments are of such severity that institutional placement is needed, several milieu therapies have been developed and used successfully. These include reality orientation therapy, remotivation and resocialization (Butler \& Lewis, 1983; Weiner \& Weinstock, 1979-80). These approaches are potentially useful with clients who are confused and/or withdrawn.

Generic counseling techniques may, and in fact should be applied in working with older disabled persons. Modifications can be made on an individual basis if counselors recognize the need to view all older persons as unique and distinct individuals. The potential for this to occur will increase in direct proportion to the knowledge counselors have of the characteristics, needs and concerns of older people in general and older disabled persons in particular. The following section includes some resources for further information about older people, their needs, and programs available to help them meet these needs. Rehabilitation counselors expecting to work 
Myers, J. E. (1983). Rehabilitation counseling for older disabled persons: The state of the art. Journal of Applied Rehabilitation Counseling, 4(3), 47-53.

Made available courtesy of The National Rehabilitation Counseling Association: http://nrca-net.org/

\section{Journal of Applied Rehabilitation Counseling}

effectively with older disabled clients can maximize their ability to do so by careful study of these resources.

Jane E. Myers, Ph.D., is Director of Rehabilitation Counselor. Education at Ohio University in Athens.

\section{Resources}

Federal agencies that coordinate or provide services for older people: U.S. Administration on Aging (counterpart of RSA), 330 C St., S.W., Washington, DC 20201; ACTION, Washington, DC 20525.

Directories of agencies and individuals that coordinate or provide services for older people may be found in the following documents:

Ganikos, M.L., Grady, K.P., Olsen, J.B., Blake, R., Fitzgerald, P.; and Lawrence, P. A handbook for conducting workshops on the counseling needs for older people. Falls Church, VA: American Personnel and Guidance Association, 1979.

Myers, J.E., Finnerty-Fried, P.F., \& Graves, C. (Eds.)Counseling older persons, Volume I, Guidelines for a team approach to training. Falls Church, VA: American Personnel and Guidance Association, 1981

Rehabilitation research and training centers conducting research on handicapped older persons: University of Pennsylvania--RT-27, School of Medicine, Philadelphia, PA 19104; Rańcho Los Amigos Hospital, University of Southern California, Los Angeles, CA.

Special issues of journals dealing with older people:

Counseling over the lifespan. Personnel and Guidance Journal, 1976.

Work-life counseling for older people. Journal of Employment Counseling, March, 1980, 17(1).

Counseling the Elderly I, II, and III. Counseling and values, February, April \& July $1980,24(2 ; 3, \& 4)$.

Rehabilitation of older persons. Journal of Rehabilitation, October, November, December 1981, 47(4).

Aging education: Perspectives and techniques for school counselors. The School Counselor, March 1982.

Assessment of older persons. Journal of Measurement and Evaluation in Guidance, October 1982, 15(3).

\section{References}

Batten, M.D. Assessing older worker policy in the U.S. Generations, May 1980 , pp. $45-45+$.

Benedict, R., \& Ganikos, M.L. Coming to terms with ageism in rehabilitation. Journal of Rehabilitation, 1981, 47(4), 10-18.

Bengston, V.L. The social psychology of aging. Indianapolis: Bobbs Merrill, 1977.

Blake, R. Disabled older persons: A demographic analysis. Journal of Rehabilitation, 1981, 47(4), 19-27.

Bozarth, J.O. The rehabilitation process and older people. Journal of Rehabilitation, 1981, 47(4), 28-32.

Brine, J.M. Psycho-social aspects of aging: An overview. In M.L. Ganikos (Ed.), Counseling the aged: $A$ training syllabus for educators. Falls Church, VA: American Personnel and Guidance Association, 1979, 65-81.

Brotman, H.B. Every ninth American: An analysis for the Chairman of the Select Committee on Aging, House of Representatives. Washington, DC: U.S. Government Printing Office, 1982 (Comm. Pub. No: 97-332).

Burgess, E.W. Aging in western societies. Chicago: University of Chicago Press, 1960.

Butler, R.N. Successful aging and the role of the life review. Geriatrics, 1974

Butler, R.N. Why survive? Being old in America: St. Louis: C.V. Mosby, 1975.

Butler, R.N. \& Lewis, M.I. Aging and mental health: Positive psychosocial approaches. St. Louis: C.V. Mosby, 1983.

Cameron, P., \& Cromer, A. Generational homophyly. Journal of Gerontology, 1974, 29(2). 232-261.

Campbell, J.A. A behavioral approach to the maintenance and rehabilitation of independent functioning with the institutionalized elderly. Dissertation Abstracts International, 1979, 39(12-B), 6111-6112.

Cape, R. Physical aspects in aging. In R. Cape (Ed.), Aging: Its compléx management. Hagerstown, MD: Harper \& Row, 1978, 13-38.
Chatfield; W.F. Economic and sociological factors influencing life satisfaction of the aged. Journal of Gerontology, 1977, 32(5), 593-599.

Cohen, G.D. Mental health services and the elderly: Needs and options. In S. Steury \& M.L. Blank (Eds.), Readings in psychotherapy with old people, Rockville, MD: National Institute of Mental Health, 1977, 68-73. ple. Rockville, MD: National Institute of Mental Health, $1977,68-73$.
anis, D.A. \& Onyemelukwe, O.I. Unique problems of the handicapped aging. In The White House Conference on Handicapped Individuals, Volume One, Awareness Papers, Washington, DC: U.S. Government Printing Office, 1977, 449-446.

Dunn, D.J. Vocational rehabilitation of the older disabled worker. Journal of Rehabilitation, 1981, 47(4), 76-81.

Edwards, J.J., \& Klemmack, D.L. Correlates of life satisfaction: A reexamination. Journal of Gerontology, 1973, 28(4), 497-502.

Flanagan, J.C. New insights to improve the quality of life at age 70. Bethesda, MD: National Institute on Aging, 1982.

Gaitz, C.M. Barriers to the delivery of psychiatric services to the elderly. The Gerontologist, 1974, 14(3), 210-214.

Goldman, R. Decline in organ function with aging. In I. Rossman (Ed.), Clinical geriatrics. Philadelphia: J.P. Lippincott, 1971.

Goldstone, H. Helping old people to continue living at home. Stop, look, listen. Review of Social Health, 1973, 98(1), 15-8.

Gryfe, C.I. Reasonable expectations in geriatric rehabilitation. Journal of the American Geriatrics Society, 1979, 27(5), 237-238.

Harel Z. Scollod, R.N., \& Bognar, B.J. Predictors of mental health among semi-rural aged. The Gerontologist, 1982, 22(6), 499-504.

Havighurst, R.J. A social-psychological perspective on aging. The Gerontologist, 1968, 8, 67-71.

Herr, J.J., \& Weaklańd, J.H. Counseling elders and their families. New York: Springfield Publishing Co., 1979.

Hodgson, J.H., \& Quinn, J.L. The impact of the triage health care delivery system upon client morale, independent living, and the cost of care. The Gerontologist, 1980, 20(3), 364-371.

Housman, R,Y., \& Bauman, N.J. Employment and older disabled person. Journal of Rehabilítation, 1981, 47(4), 82-83.

Hunt, T.E. Practical considerations in the rehabilitation of the aged. Journal of the American Geriatrics Society, 1980, 28(2), 59-64.

Jarvikowski, A \& Lahelma, E. Early rehabilitation at the work place. New York: World Rehabilitation Fund, 1980.

Jernigan, J.A. Loss of physical function and disability: Health problems of older persons. Journal of Rehabilitation, 1981, 47(4), 34-37.

Kasschau, P.L. Perceived age discrimination in a sample of aerospace employees. The Gerontologist, 1976, 16(2), 166-173.

Kastenbaum, R. Death and bereavement in later life. In A.H. Kutscher (Ed.), Death and bereavement. Springfield, IL: C.C. Thomas, 1969.

Kobrynski, B. Rehabilitation of the elderly patient. Journal of the American Geriatric Society, 1966, 14(4), 400-406.

Lawrence, P. Applying skills with special populations. In J.E. Myers (Ed.), Counseling older persons, Volume III, Trainer's manual for basic helping skills. Falls Church, VA: American Personnel and Guidance Association, 1981

Liang, J., \& Bollen, K.A. The structure of the Philadelphia Geriatric Center Morale Scale: A reinterpretation. Journal of Gerontology, 1983, 38(2), 181-189.

Lobuts, J.E. A project to demonstrate the role of a rehabilitation team in providing comprehensive services to the older legally blind on an itinerant basis. Final report. Charleston: West Virginia Department of Education, 1977.

Lowenthal, M.F., \& Haven, C. Interaction and adaptation: Intimacy as a critical variable. In B.L. Neugarten (Ed.), Middle age and aging. Chicago: University of Chicago Press, 1968.

Loyola, U. Educative/psychotherapeutic rehabilitation groups following myocardial infarction: A study of denial and depression in the post infarct patient. Dissertation Abstracts International, 1979, 38(11-B), 5566.

Macione, A. Physiological changes and common health problems of aging. In M.L. Ganikos (Ed.), Counseling the aged: $A$ training syllabus for educators. Falls Church, VA: American Personnel and Guidance Association, 1979.

McTavish, D.G. Perceptions of old people: A review of research methodologies and findings. The Gerontologist, 1971, 11(4), 90-101.

Myers, J.E. Counseling the disabled older person for the world of work. Journal of employment counseling, 1980, 17(1), 37-48.

Myers, J.E. Rehabilitation of older persons: The state of the art. In Annual review of rehabilitation. New York: Springer, 1983.

Myers, J.E., \& Loesch, L.C. The counseling needs of older persons. The Humanist Educator, 1981, 20(1), 21-35.

National Institute on Aging. Progress report on Senile Dementia of the Alzheimer's Type. Bethesda, MD: National Institute of Health, 1981.

Neugarten, B.L. Psychology of aging. Washington, DC: American Psychological Association, 1976. 
Myers, J. E. (1983). Rehabilitation counseling for older disabled persons: The state of the art. Journal of Applied Rehabilitation Counseling, 4(3), 47-53. Made available courtesy of The National Rehabilitation Counseling Association: http://nrca-net.org/

\author{
Volume 14, Number 3, Fall 1983
}

Neugarten, B., Havighurst, R., \& Tobin, S. Personality and patterns of aging. In $B$. Neugarten (Ed.), Middle age and aging. Chicago: University of Chicago Press, 1968.

Ohio, Governor's Commission on Aging. Ohio's senior citizens. Columbus: State of Ohio, 1960.

Organization for Economic Cooperation and Development. Promoting the placement of older workers. Paris, France: Author, 1967.

Pfeiffer, E. Multidimensional functional assessment. The OARS methodology. A manual. Durham, NC: Duke University Center for the Study of Aging and Human Development, 1976.

Pfeiffer, E., \& Busse, E. Mental disorders in late life--Affective disorders: Paranoid, neurotic, and situational reactions. In E. Bussee \& E. Pfeiffer (Eds.), Mental illness in later life. Washington, DC: American Psychiatric Association, 1973.

Preston, R.P. The dilemmas of care: social and nursing adaptations to the deformed, the disabled and the aged. New York: Elsevier North Holland, Inc., 1979.

Puner, M. To the good long life: What we know about growing old. New York: Universe Books, 1974.

Radzyminski, S.F. Symposium on care and rehabilitation of the geriatric patient, part 1: Introduction and general considerations. Journal of the American Geriatries Society, 1969, 17(12), 1134-1165.

Rasch, J. D., Crystal, R.M. \& Thomas, K.R. The perception of the older adult: A study of trainee attitudes. Journal of Applied Rehabilitation Counseling, 1977, 8(2), 121-127.

Rehab. Group, Inc. Digest of data on persons with disabilities. Washington, DC: U.S. Government Printing Office, 1979 (Stock No. 017-090-00050-0).

Rosenbloom, A.A. Prognostic factors in the visual rehabilitation of aging patients. New Outlook for the Blind, 1974, 68(3), 124-127.

Rusk, H.A. Rehabilitation medicine. St. Louis: C.V. Mosby, 1977.

Salmon, H.E. How can I make the best use of support networks. In J.E. Myers (Ed.), Counseling older persons, Volume III, A trainer's manual for basic helping skills. Falls Church, VA: American Personnel and Guidance Association, 1981A.

Salmon, H.E. Theories of aging, disability and loss. Journal of Rehabilitation, 1981B, 47(4), 44-50.

Schow, R.L., Christensen, J.M., Hutchinson, J.M., \& Nerbonne, M.A. Com? munication disorders of the aged: $A$ guide for health professionals. Baltimore: MD: University Park Press, 1978.

Sheppard, H.L. New perspectives on older workers. Washington, DC: The W.E. Upjohn Institute for Employment Research, 1971.

Sherman, E.D., \& Gingras, G. Rehabilitation of the aged. Canadian Medical Association Journal, 1965, 93(15), 797-800.
Siegel, J.S. Prospective trends in the size and structure of the elderly population, impact of mortality trends, and some implications (Statement before the Select Committee for Aging and the Select Commission on Population, U.S. House of Representatives, May 24, 1978). Superintendent of Documents Y4. P81: 95/9, 1978.

Simpson, I.H., McKinney, J.C. (Eds.) Social aspects of aging. Durham, NC: Duke University Press, 1966.

Smith, E. Helping old people to continue living at home. Development of new methods. Review of Social Health, 1978, 98(1), 11-14.

Solomon, K., \& Vickers, R. Attitudes of health workers toward old people. Journal of the American Geriatrics Society, 1979, 27(4), 186-191.

Stickle, F. Satisfying the emotional needs of the elderly: A call for counselors. Counseling and values, 1977, 21(3), 180-184.

Strehler, B.L. Time, cells, and aging. New York: Academic Press, 1962, 1977.

Thomas, P. Experiences of two preventive clinics for the elderly. British Medical Journal, 1968, 2(601), 357-360.

Townsend, P. The family life of old people. Boston: Routledge \& Kegan Paul, 1957.

Waters, E. \& Weaver, A.L. Specialized techniques to help older people. In J.E. Myers (Ed.), Counseling older persons, Volume III, A trainer's manual for basic helping skills. Falls Church, VA: American Personnel and Guidance Association, 1981.

Weiner, M.B., \& Weinstock, C.S. Group progress of community elderly as measured by tape recordings, group tempo and group evaluations. International Journal of Aging Human Development, 1979-80, 10(2), 177-185.

Williams, M.G. Independent living and older people. Journal of Rehabillitation, $1981,47(4), 69-71$.

Wolcott, L.E., \& Wheeler, P.C. Rehabilitation and the aged. In A.B. Chirn (Ed.), Working with older people, Volume IV, clinical aspects of aging. Washington, DC: USDHEW, PHS, 1971.

Youmans, E.G. Attitudes: Young-old and old-old. The Gerontologist, 1977, 17(2), 178-188. 